\title{
A cross-study gene set enrichment analysis identifies critical pathways in endometriosis Hongbo Zhao ${ }^{1,2}$, Qishan Wang1,2, Chunyan Bai ${ }^{1,2}$, Kan $\mathrm{He}^{1,2}$ and Yuchun Pan*1,2
}

\author{
Address: ${ }^{1}$ School of Agriculture and Biology, Shanghai Jiao Tong University, Shanghai, PR China and ${ }^{2}$ Shanghai Key Lab for Veterinary \\ Biotechnology, Shanghai, 200240, PR China \\ Email: Hongbo Zhao - zhaohb@sjtu.edu.cn; Qishan Wang - wangqishan@sjtu.edu.cn; Chunyan Bai - bcy_6@hotmail.com; \\ Kan He - birett@sjtu.edu.cn; Yuchun Pan* - panyuchun1963@yahoo.com.cn \\ * Corresponding author
}

Published: 8 September 2009

Reproductive Biology and Endocrinology 2009, 7:94 doi:10.1186/1477-7827-7-94

This article is available from: http://www.rbej.com/content/7/1/94

(c) 2009 Zhao et al; licensee BioMed Central Ltd.

This is an Open Access article distributed under the terms of the Creative Commons Attribution License (http://creativecommons.org/licenses/by/2.0), which permits unrestricted use, distribution, and reproduction in any medium, provided the original work is properly cited.
Received: 26 April 2009

Accepted: 8 September 2009

\begin{abstract}
Background: Endometriosis is an enigmatic disease. Gene expression profiling of endometriosis has been used in several studies, but few studies went further to classify subtypes of endometriosis based on expression patterns and to identify possible pathways involved in endometriosis. Some of the observed pathways are more inconsistent between the studies, and these candidate pathways presumably only represent a fraction of the pathways involved in endometriosis.
\end{abstract}

Methods: We applied a standardised microarray preprocessing and gene set enrichment analysis to six independent studies, and demonstrated increased concordance between these gene datasets.

Results: We find 16 up-regulated and 19 down-regulated pathways common in ovarian endometriosis data sets, 22 up-regulated and one down-regulated pathway common in peritoneal endometriosis data sets. Among them, 12 up-regulated and I down-regulated were found consistent between ovarian and peritoneal endometriosis. The main canonical pathways identified are related to immunological and inflammatory disease. Early secretory phase has the most overrepresented pathways in the three uterine cycle phases. There are no overlapping significant pathways between the dataset from human endometrial endothelial cells and the datasets from ovarian endometriosis which used whole tissues.

Conclusion: The study of complex diseases through pathway analysis is able to highlight genes weakly connected to the phenotype which may be difficult to detect by using classical univariate statistics. By standardised microarray preprocessing and GSEA, we have increased the concordance in identifying many biological mechanisms involved in endometriosis. The identified gene pathways will shed light on the understanding of endometriosis and promote the development of novel therapies.

\section{Background}

Endometriosis is defined as the presence of endometriumlike tissue in sites outside the uterine cavity and occurs in
$6-10 \%$ of women in the general population [1]. The main clinical features are chronic pelvic pain, pain during intercourse, and infertility [2]. As cellular and molecular mech- 
anisms involved in endometriosis are still uncovered, the classification of this disease evolved from a local disorder to a complex, chronic systemic disease [3]. Despite extensive researches, the etiology of endometriosis remains obscure. Gene expression profiling has been used in several studies of endometriosis, in which from a few to hundreds differentially expressed genes were identified [4-17]. For previously identified genes, their roles in the pathogenesis of endometriosis are further discussed. But it is hard to interpret individual genes on a list with many significant genes.

A common challenge in the analysis of genome wide expression no longer lies in obtaining gene expression profiles, but rather in interpreting the results to gain insights into biological mechanisms [18]. Pathway analysis of microarray data evaluates gene expression profiles of a priori defined biological pathways in association with a phenotype of interest. Recently gene expression patterns were further used in the classification of subtypes of endometriosis as well as in the identification of the pathways involved in endometriosis [4,13-16]. So far the observed pathways were discordant between the studies that suggest that these previously identified pathways only represent a fraction of the pathways involved in endometriosis.

Currently the most well-known and widely used approach to gene set analysis, the Gene Set Enrichment Analysis (GSEA) method was introduced by Mootha et al. [19], which was used to identify pre-defined gene sets which exhibited significant differences in expression between samples from normal and patients. The methodology was subsequently refined by Subramanian et al. [18]. The algorithms calculate the statistical significance of the expression changes across groups or pathways rather than individual gene, thus allowing identification of groups or pathways most strongly affected by the observed expression changes. The analysis based on a group of relevant genes instead of on an individual gene increases the like- lihood for investigators to identify the critical functional processes under the biological phenomena under study. GSEA is likely to be more powerful than conventional single-gene methods in the study of complex diseases in which many genes make subtle contributions [20].

In a single data set the GSEA will generally not result in significant findings beyond major pathways. Here we will use standardised microarray preprocessing and GSEA with comprehensive expression profiles in an attempt to find greater data convergence and provide a systematic insight into the pathways altered during endometriosis pathogenesis.

\section{Methods \\ Datasets}

We searched GEO http://www.ncbi.nlm.nih.gov/geo/, and ArrayExpress http://www.ebi.ac.uk/arrayexpress/ for the gene expression profiling studies related to endometriosis disease. Data were included in our re-analysis if they met the following conditions: 1) the data is in genomewide; 2) comparison was conducted between endometriosis patients and controls; 3 ) complete microarray raw or normalized data are available.

Finally six public gene expression data sets were involved in our study, which assessed endometriosis transcripts on a genome-wide basis. In data set GSE7307, total 677 samples from more than 90 distinct tissue types were processed, but only the profiles related to endometriosis and eutopic endometrium were considered here. The data generated from human endometrial endothelial cells by Sha et al. [4] were also included in our combined re-analysis to compare with the whole endometriosis tissues data sets. The related information about these datasets, such as the microarray platform, sample type, sample size, is listed in Table 1.

Table I: Characteristics of datasets included in the studies.

\begin{tabular}{|c|c|c|c|c|c|c|c|}
\hline \multirow{2}{*}{$\begin{array}{l}\text { First Author } \\
\text { or Contributor }\end{array}$} & \multirow[t]{2}{*}{ Chip } & \multirow[t]{2}{*}{ GEO Accession } & \multirow[t]{2}{*}{ Experimental design } & \multirow[t]{2}{*}{ Classification } & \multirow[t]{2}{*}{ Probes } & \multicolumn{2}{|c|}{ Number of samples } \\
\hline & & & & & & Disease & Normal \\
\hline Sha $[4]$ & UI33 PLUS 2.0 & GSE7846 & unpaired, HEECS & ovarian & $54 \mathrm{~K}$ & 5 & 5 \\
\hline Burney [14] & UI33 PLUS 2.0 & GSE6364 & unpaired, tissues & $\begin{array}{l}\text { Ovarian, peritoneal, } \\
\text { rectovaginal }\end{array}$ & $54 \mathrm{~K}$ & 21 & 16 \\
\hline Eyster [15] & CodeLink & GSE5 I08 & paired, tissues & Ovarian, peritoneal & $55 \mathrm{~K}$ & $6 / 5$ & $6 / 5$ \\
\hline Hever [16] & UI33 PLUS 2.0 & GSE7305 & paired, tissues & ovarian & $54 \mathrm{~K}$ & 10 & 10 \\
\hline Roth & UI33 PLUS 2.0 & GSE7307 & unpaired, tissues & ovarian & $54 \mathrm{~K}$ & 18 & 23 \\
\hline Hull [I7] & UI33A & GSEI I69I & paired, tissues & peritoneal & $22 K$ & 9 & 9 \\
\hline
\end{tabular}

paried: compare eutopic endometrium to ectopic endometrium from the same patients with entire endometrial tissue. unparied: compare eutopic endometrium from women with endometriosis to eutopic endometrium from women without endometriosis. HEECS: human endometrial endothelial cells samples. 


\section{Data Preprocessing}

Data preprocessing was performed using software packages developed in version 2.4.0 of Bioconductor [21] and $\mathrm{R}$ version 2.9.0 [22]. Each Affymetrix dataset was background adjusted, normalized and $\log 2$ probe-set intensities calculated using the Robust Multichip Averaging (RMA) algorithm in affy package $[23,24]$, and the Codelink arrays normalizations performed in GSE5108 were retained. Genes which cannot be mapped to any KEGG pathway identified were excluded from the further analysis. The interquartile range (IQR) was used as a measure of variability. From the resulting distribution of IQR values for all genes we set a cut-off so as to exclude values under 0.5. When multiple probe sets target one gene, the probe set with largest variability was kept. Pathway analysis was performed separately in each data set.

\section{Gene set enrichment analysis of pathways}

GSEA implemented in the Category package (version 2.10.1 [25]). The goal of GSEA is to determine whether the members of a gene set $S$ randomly distributed throughout the entire reference gene list $L$ or are primarily found at the top or bottom. One of the advantages of GSEA is the relative robustness to noise and outliers in the data. The gene sets represented by less than 10 genes were excluded. The t-statistic mean of the genes was computed in each pathway. Using a permutation test with 1000 times, the significantly changed pathways were identified with $\mathrm{p}$-value $\leq 0.05$.

\section{Results}

For the studies which used multiple locations (ovarian and peritoneal) or uterine cycle phases (proliferative to secretory) of endometriosis, each type or phase was treated as a separate data set. These six studies provided 9 case-control data sets including 74 endometriosis cases and 74 controls. Common GSEA method was applied to the 9 datasets. For individual analysis, we obtained the significant pathways and the genes included [See Additional file 1, 2, 3 and 4]. The analysis results were summarised in table 2 . We postulated that the pathways and genes that appear consistently as different expressed in multiple studies are more likely to be important in endometriosis. To look for such convergence we compared the GSEA results.

\section{Common significant pathways in ovarian endometriosis}

Endometriosis is most commonly localized in the ovaries. We first compared the ovarian endometriosis data sets for their convergence and reproducibility. The results for the ovarian endometriosis data sets were presented in Table 3. Based on the permutation p-values, the GSEA reported 24 \& 31 (Eyster data set), 56 \& 59 (Hever data set), and 36 \& 44 (Roth data set) up- and down- regulated pathways. The overlaps among them are presented in Figure 1, with 16 up-regulated and 19 down-regulated pathway detected in common. Among the up-regulated list, the main canonical pathways affected are related to immunological and inflammatory diseases including Asthma, Autoimmune thyroid disease, Systemic lupus erythematosus, Allograft rejection, Graft-versus-host disease and Type I diabetes mellitus. Cytokine-cytokine receptor interaction and Cell adhesion molecules (CAMs) belongs to signaling molecules and interaction. PPAR signaling pathway is part of endocrine system. The most down-regulated pathways are metabolism and repair related pathways. And we extracted the collective genes in each pathway from the 3 data sets [See Additional file 5].

Common significant pathways in peritoneal endometriosis We also analyzed the data sets from peritoneal endometriosis which is another important endometriosis type. 23

Table 2: Summary of each data set used in the re-analysis and the number of differentially expressed pathways.

\begin{tabular}{|c|c|c|c|c|c|c|}
\hline Studies & $\begin{array}{l}\text { Number of } \\
\text { patients }\end{array}$ & $\begin{array}{l}\text { Number of } \\
\text { controls }\end{array}$ & $\begin{array}{l}\text { Number of genes } \\
\text { after preprocessing }\end{array}$ & $\begin{array}{l}\text { Number of } \\
\text { pathways have } \\
\text { genes } \geq 10\end{array}$ & $\begin{array}{l}\text { Up-regulated } \\
\text { pathways }\end{array}$ & $\begin{array}{l}\text { Down-regulated } \\
\text { pathways }\end{array}$ \\
\hline \multicolumn{7}{|c|}{ Ovarian Data Sets } \\
\hline Eyster & 6 & 6 & 3105 & 171 & 24 & 31 \\
\hline Hever & 10 & 10 & 1930 & 139 & 56 & 59 \\
\hline Roth & 18 & 23 & 2575 & 154 & 36 & 44 \\
\hline \multicolumn{7}{|c|}{ Peritoneal Data Sets } \\
\hline Eyster & 5 & 5 & 3084 & 171 & 57 & 11 \\
\hline Hull & 9 & 9 & 1255 & 113 & 29 & 7 \\
\hline \multicolumn{7}{|c|}{ Uterine cycle Data Sets } \\
\hline Burney_Pro & 6 & 5 & 1900 & 138 & 4 & 3 \\
\hline Burney_ES & 6 & 3 & $147 \mid$ & 122 & 12 & 21 \\
\hline Burney_MS & 9 & 8 & 952 & 93 & 0 & 22 \\
\hline \multicolumn{7}{|c|}{ Human endometrial endothelial cells Data Set } \\
\hline Sha & 5 & 5 & 2324 & 153 & 44 & 1 \\
\hline
\end{tabular}

Pro, Proliferative; ES, early secretory; MS, midsecretory Proliferative 
(a)
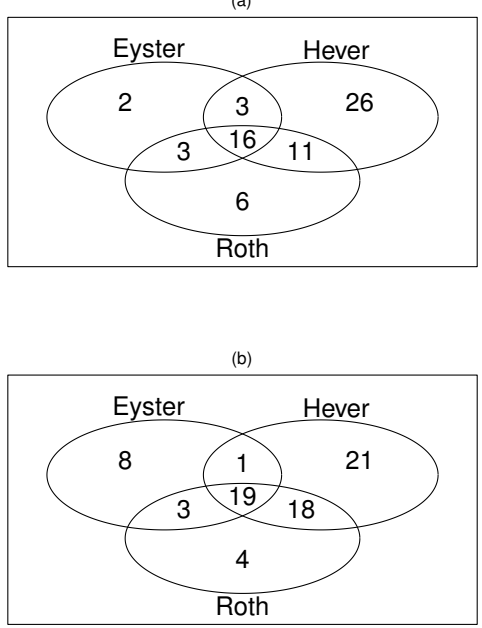

Figure I

Significant pathways identified and overlap between the 3 ovarian endometriosis data sets. For each data set, GSEA implanted to generate $p$-values for each pathway and using a permutation test with 1000 times, obtained the significant pathways with $p$-value cut-off of $\leq 0.05$. (a) GSEA detected 24 (Eyster data set), 56 (Hever data set) and 36 (Roth data set) up-regulated pathways and 16 are common. (b) GSEA detected 31 (Eyster data set), 59 (Hever data set) and 44(Roth data set) down-regulated pathways and 19 are common.

pathways were commonly significantly regulated in the two peritoneal endometriosis data sets, summarised in table 4 and Figure 2. Of these 23 pathways, 12 up- and one down- regulation pathways were also identified from the three ovarian endometriosis data sets. The significances of four pathways (Drug metabolism - cytochrome P450, Metabolism of xenobiotics by cytochrome P450, Olfactory transduction, Toll-like receptor signaling pathway) were found from the data of Eyster et al. [15], but not in the data of Hull et al. [17]. Collective genes in each pathway were extracted [See Additional file 6].

\section{Differential pathways between the timing of the uterine cycle}

Burney et al. conducted global gene expression analysis of endometrium from women with and without moderate/ severe stage endometriosis and compared the gene expression signatures across various phases of the menstrual cycle [14]. Specimens were classified as proliferative (PE, d 8-14), early secretory (ESE, d 15-18), midsecretory (MSE, d 19-23). They did not examine later than Day 23 in the menstrual cycle. Each phase had endometriosis more than one type. We re-analyzed their microarray CEL files and each phase was treated as a separate data set. In proliferative phase, 4 pathways were up-regulated and 3 pathways were down-regulated. Early secretory phase had the most over-represented pathways, 12 were up-regulated and 21 were down-regulated. There is no significant pathway up-regulated at $\mathrm{p} \leq 0.05$ in midsecretory phase while 22 down-regulated pathways were identified [See Additional file 3]. The overlap of pathways among these phases is very low (Figure 3 ).

\section{Differential expression in human endometrial endothelial cells}

Sha et al. selected the eutopic endothelial compartment as the subject for exploring the differential expression profile between endometriosis patients and normal controls [4]. Our re-analysis revealed 44 up-regulated and 1 down-regulated pathways in the dataset [See Additional file 4]. There is no overlap compared with the common list from ovarian endometriosis data sets using the whole tissue as sample.

\section{Discussion}

Endometriosis is an enigmatic disease. No existing single theory can explain all cases of endometriosis. The genome-wide microarrays are very powerful because they allow the identification of gene families or pathways that change in concert in a disease state comprehensively. Biologically relevant inference should therefore be reproducible across laboratories. For single gene analysis, different statistical methods and different datasets examining the same biological condition may lead to significant discrepancies [26]. Pathways analysis applied to different datasets yields interesting common results, diminishing the large discrepancies observed in direct comparisons of lists of differentially expressed genes obtained from different datasets. Therefore, the study of complex diseases through pathway analysis is able to highlight genes weakly connected to the phenotype which may be difficult to detect by using classical univariate statistics.

We have performed gene set enrichment analysis of six independent publicly available gene expression data sets to understand in depth the common biological mechanisms involved in endometriosis. Our study compared the gene expression between lesion locations (ovarian vs. peritoneal), phases of the uterine cycle (proliferative to midsecretory) and cell types (endometrial endothelial cells vs. whole tissue), as well as overall eutopic versus ectopic endometrium. The transcriptomes of eutopic endometrium and ectopic endometrial lesions suggest that ovarian endometriosis and peritoneal disease are different disorders [13]. Our findings suggest that most of the pathways impacted the ovarian and peritoneal endometriosis are consistent. Many of differentially expressed pathways found in this study have already been reported to be involved in endometriosis pathogenesis. Here, this discussion presents several of the differentially 
Table 3: Common pathway categories identified by GSEA of the 3 ovarian endometriosis datasets

\begin{tabular}{|c|c|c|}
\hline Pathway name & Classification & Genes \\
\hline \multicolumn{3}{|l|}{ Up-regulation } \\
\hline PPAR signaling pathway & Endocrine System & 26 \\
\hline Cytokine-cytokine receptor interaction & Signaling Molecules and Interaction & 84 \\
\hline Cell adhesion molecules (CAMs) & Signaling Molecules and Interaction & 68 \\
\hline Complement and coagulation cascades & Immune System & 32 \\
\hline Toll-like receptor signaling pathway & Immune System & 37 \\
\hline Hematopoietic cell lineage & Immune System & 36 \\
\hline Asthma & Immune Disorders & 12 \\
\hline Autoimmune thyroid disease & Immune Disorders & 16 \\
\hline Systemic lupus erythematosus & Immune Disorders & 29 \\
\hline Allograft rejection & Immune Disorders & 16 \\
\hline Graft-versus-host disease & Immune Disorders & 17 \\
\hline Arachidonic acid metabolism & Lipid Metabolism & 19 \\
\hline Metabolism of xenobiotics by cytochrome P450 & Xenobiotics Biodegradation and Metabolism & 19 \\
\hline Drug metabolism - cytochrome P450 & Xenobiotics Biodegradation and Metabolism & 20 \\
\hline Type I diabetes mellitus & Metabolic Disorders & 19 \\
\hline Olfactory transduction & Sensory System & 4 \\
\hline \multicolumn{3}{|l|}{ Down-regulation } \\
\hline Fatty acid metabolism & Lipid Metabolism & 21 \\
\hline Androgen and estrogen metabolism & Lipid Metabolism & 5 \\
\hline Sphingolipid metabolism & Lipid Metabolism & 18 \\
\hline Oxidative phosphorylation & Energy Metabolism & 44 \\
\hline Citrate cycle (TCA cycle) & Carbohydrate Metabolism & 13 \\
\hline Butanoate metabolism & Carbohydrate Metabolism & 12 \\
\hline Pyrimidine metabolism & Nucleotide Metabolism & 36 \\
\hline Glycosylphosphatidylinositol(GPI)-anchor biosynthesis & Glycan Biosynthesis and Metabolism & 10 \\
\hline Lysine degradation & Amino Acid Metabolism & 19 \\
\hline Folate biosynthesis & Metabolism of Cofactors and Vitamins & 10 \\
\hline DNA polymerase & Replication and Repair & 22 \\
\hline Base excision repair & Replication and Repair & 16 \\
\hline Nucleotide excision repair & Replication and Repair & 19 \\
\hline Mismatch repair & Replication and Repair & 13 \\
\hline Homologous recombination & Replication and Repair & 10 \\
\hline Cell cycle & Cell Growth and Death & 57 \\
\hline Thyroid cancer & Cancers & 15 \\
\hline Proteasome & Folding, Sorting and Degradation & 13 \\
\hline Ubiquitin mediated proteolysis & Folding, Sorting and Degradation & 50 \\
\hline
\end{tabular}

Genes: Number of common genes included in the pathway.

expressed pathways and hypotheses regarding the role of these pathways in endometriosis.

Most significant of the common up-regulated pathways are involved in immune system and immune disorders. It has been widely documented that endometriosis, as an inflammatory disease, induces an immune response, leading to both cellular and humoral immune changes $[27,28]$. The association between endometriosis and immune disorders were literature supported [29]. Also some studies concluded that women with endometriosis do not have a higher risk of having asthma, systemic lupus erythematosus and Sjögren's syndrome than other subjects [30,31]. Our GSEA results showed that expression of Asthma, Graft-versus-host disease, Autoimmune thyroid disease, Allograft rejection, Systemic lupus erythematosus and Type I diabetes mellitus pathways are the significantly imbalanced between endometriosis and eutopic endometrium. We found that human leukocyte antigen (HLA) genes are critical genes in these pathways. HLA are key components of the major histocompatibility complex (MHC), which is involved in immune cell signalling processes such as T-cell activation. People with certain HLA antigens are more likely to develop certain autoimmune diseases, such as Type I Diabetes, Ankylosing spondylitis, Celiac Disease, Systemic Lupus Erythematosus, Myasthenia Gravis and Sjögren's syndrome et al [32].

Cytokine-cytokine receptor interaction and Cell adhesion molecules (CAMs) included in GSEA were up-regulated in endometriosis. Cell adhesion molecules are (glyco) proteins expressed on the cell surface and play a critical role 

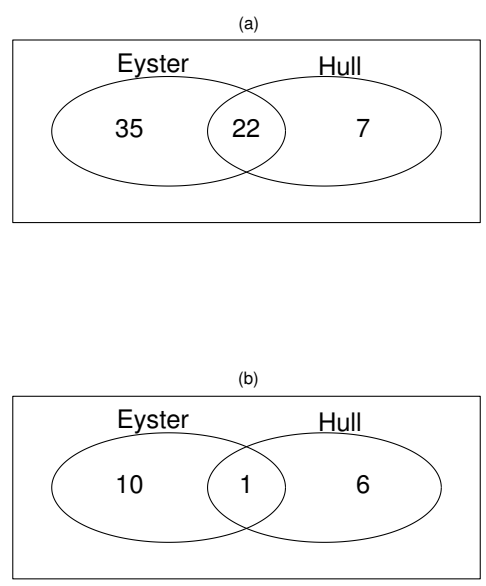

\section{Figure 2}

Significant pathways identified and overlap between the $\mathbf{2}$ peritoneal endometriosis data sets. For each data set, GSEA implanted to generate $p$-values for each pathway and using a permutation test with 1000 times, obtained the significant pathways with $p$-value cut-off of $\leq 0.05$. (a) GSEA detected 57 (Eyster data set) and 29 (Hull data set) up-regulated pathways and 22 are common. (b) GSEA detected II (Eyster data set) and 7 (Hull data set) down-regulated pathways and $\mathrm{I}$ is common. in a wide array of biologic processes that include hemostasis, the immune response, inflammation, embryogenesis, and development of neuronal tissue. Clinical observations and in vitro experiments imply that endometriotic cells are invasive and able to metastasize. Analogous to tumour metastasis, it is likely that cell adhesion molecules are central for the invasion and metastasis of endometriotic cells. The expression of some integrins is aberrant in endometriotic lesions compared to eutopic endometrium [33]. Cytokines are key mediators of intercellular communication within the immune system. Several cytokines including interleukin (IL)-1, 6, 8, 10, tumor necrosis factor (TNF)- $\alpha$, and vascular endothelial growth factor (VEGF) were reported to be increased in the peritoneal fluid (PF) of women with endometriosis [34-41]. Peroxisome proliferator-activated receptors (PPARs) signaling pathway is up-regulated according to GSEA. PPAR are nuclear hormone receptors that are activated by fatty acids and their derivatives. PPAR- $\gamma$ is present in human ovarian cells. Activation of PPAR- $\gamma$ enhances steroidogenesis via activation of StAR protein and leads to the activation of insulin-signaling pathways [42].

The expression patterns of ER (estrogen receptors) and PR (progesterone receptors) in endometriotic lesions are different from those in the eutopic endometrium. Endome-

Table 4: Common pathway categories identified by GSEA of the 2 peritoneal endometriosis datasets

\begin{tabular}{|c|c|c|}
\hline Pathway name & Classification & Genes \\
\hline \multicolumn{3}{|l|}{ Up-regulation } \\
\hline Cell Communication & Cell Communication & 42 \\
\hline Focal adhesion & Cell Communication & 91 \\
\hline Regulation of actin cytoskeleton & Cell Motility & 61 \\
\hline PPAR signaling pathway & Endocrine System & 19 \\
\hline Calcium signaling pathway & Signal Transduction & 41 \\
\hline VEGF signaling pathway & Signal Transduction & 25 \\
\hline Cytokine-cytokine receptor interaction & Signaling Molecules and Interaction & 58 \\
\hline Neuroactive ligand-receptor interactio & Signaling Molecules and Interaction & 20 \\
\hline ECM-receptor interaction & Signaling Molecules and Interaction & 46 \\
\hline Cell adhesion molecules (CAMs) & Signaling Molecules and Interaction & 49 \\
\hline Complement and coagulation cascades & Immune System & 29 \\
\hline Hematopoietic cell lineage & Immune System & 29 \\
\hline Leukocyte transendothelial migration & Immune System & 44 \\
\hline Asthma & Immune Disorders & 7 \\
\hline Autoimmune thyroid disease & Immune Disorders & 12 \\
\hline Systemic lupus erythematosus & Immune Disorders & 20 \\
\hline Allograft rejection & Immune Disorders & 12 \\
\hline Graft-versus-host disease & Immune Disorders & 15 \\
\hline Arachidonic acid metabolism & Lipid Metabolism & 16 \\
\hline Type I diabetes mellitus & Metabolic Disorders & 15 \\
\hline Pancreatic cancer & Cancers & 24 \\
\hline Glioma & Cancers & 21 \\
\hline \multicolumn{3}{|l|}{ Down-regulation } \\
\hline Sphingolipid metabolism & Lipid Metabolism & 13 \\
\hline
\end{tabular}

Genes: Number of common genes included in the pathway. 

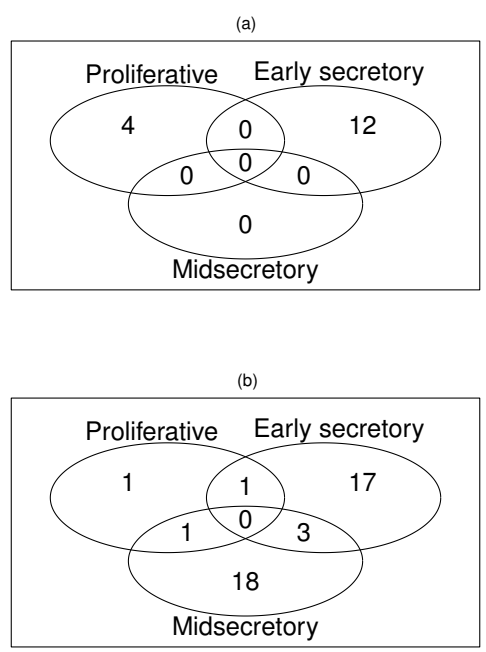

Figure 3

Significant pathways identified and overlap between the phases of uterine cycle. For each phase, GSEA implanted to generate $p$-values for each pathway and using a permutation test with 1000 times, obtained the significant pathways with $\mathrm{p}$-value cut-off of $\leq 0.05$. (a) GSEA detected 4 (Proliferative phase), 12 (Early secretory phase) and 0 (Mid secretory phase) up-regulated pathways and no overlap. (a) GSEA detected 3 (Proliferative phase), 2I (Early secretory phase) and 22 (Mid secretory phase) down-regulated pathways and the overlap is very low.

triosis is an estrogen-dependent disease [43]. Studies of hormone-ligand binding assays and enzyme immunoassays showed a consistent reduction in the content of ER and PR in endometriotic implants [44-47]. Androgen and estrogen metabolism pathway appeared in most of our re-analysis results. Oxidative phosphorylation pathway possibly affect oocyte quality, fertilization rate, and further embryo development [48], is down-regulated in our analysis.

Burney et al. studied proliferative, early secretory and midsecretory eutopic endometrium (up to Day 23), from women with endometriosis and controls. They found that endometrial gene expression differed most, between these groups, in the early secretory phase (Days 15-18). They found far fewer differences in the mid-secretory phase where no transcripts were found to be up- or down-regulated 4-fold. The result is consistent with the findings of other studies $[12,49,50]$. Corresponding to their result, there is no significant up-regulated pathway in mid-secretory phase by our GSEA. The molecular phenotype of midsecretory, eutopic endometrium from women with endometriosis and from controls appears to be very similar [50]. Current efforts to develop minimally invasive diagnostic tests for the presence of endometriosis and also tests to distinguish minimal/mild and moderate/severe disease, by sampling the endometrium, should be focused on the early secretory phase of the menstrual cycle [50].

We hypothesize that all cell types in the endometriotic lesion contribute to the pathology of the disease. Matsuzaki et al. compared global gene expression in eutopic endometrium, from controls and patients with deep endometriosis, at various time points throughout the menstrual cycle. They found no genes were up- or downregulated in all phases of the cycle, in either tissue compartments [12]. None of the genes from their study that had been identified as differentially expressed in either the stromal or epithelial compartments was shown to be differentially expressed. This may be due to the relative contribution that the epithelial and stromal transcriptomes make to whole tissue gene expression. Our GSEA result showed that the significant pathways from the human endometrial endothelial cells had low overlap with the list from ovarian endometriosis data sets used whole tissue.

\section{Conclusion}

The pathogenesis of endometriosis is likely multifactorial. A deeper understanding of the mechanisms of these diseases can be reached by focusing on deregulation of gene sets or pathways rather than on individual genes. By standardised microarray preprocessing and GSEA, we have increased the concordance to identify many biological mechanisms are involved in endometriosis which are novel in terms of their connection to endometriosis (as mined from the existing literature). More studies about the specific role and interactions of the genes included in related pathways are needed to improve the understanding of endometriosis.

\section{Competing interests}

The authors declare that they have no competing interests.

\section{Authors' contributions}

HBZ and YCP conceived and designed the study. HBZ contributed the data analysis and drafted the manuscript. $\mathrm{KH}$ performed data collection. QSW and CYB mined the literature and manuscript drafting. All authors read and approved the final manuscript.

\section{Additional material}

\section{Additional file 1}

Table 5: Pathway analysis of ovarian endometriosis data sets. The data provided represent the list of significant pathways identified by GSEA in the 3 ovarian endometriosis data sets.

Click here for file

[http://www.biomedcentral.com/content/supplementary/14777827-7-94-S1.xls] 


\section{Additional file 2}

Table 6: Pathway analysis of peritoneal endometriosis data sets. The data provided represent the list of significant pathways identified by GSEA in the 2 peritoneal endometriosis data sets.

Click here for file

[http://www.biomedcentral.com/content/supplementary/14777827-7-94-S2.xls]

\section{Additional file 3}

Table 7: Pathway analysis between the timing of the uterine cycle. The data provided represent the list of significant pathways identified by GSEA between the timing of the uterine cycle.

Click here for file

[http://www.biomedcentral.com/content/supplementary/14777827-7-94-S3.xls]

\section{Additional file 4}

Table 8: Pathway analysis in the specific phenotype of HEECs from endometriosis. The data provided represent the list of significant pathways identified by GSEA involved in the specific phenotype of HEECs from endometriosis.

Click here for file

[http://www.biomedcentral.com/content/supplementary/1477-

7827-7-94-S4.xls]

\section{Additional file 5}

Table 9: Common significant pathways in ovarian endometriosis data sets. The data provided represent the list of common significant pathways from GSEA of the 3 ovarian endometriosis datasets.

Click here for file

[http://www.biomedcentral.com/content/supplementary/1477-

7827-7-94-S5.xls]

\section{Additional file 6}

Table 10: Common significant pathways in peritoneal endometriosis data sets. The data provided represent the list of common significant pathways from GSEA of the 2 peritoneal endometriosis datasets.

Click here for file

[http://www.biomedcentral.com/content/supplementary/14777827-7-94-S6.xls]

\section{Acknowledgements}

This work was supported by the National Natural Science Foundation of China (grant numbers 3087 I 782 and 3067| 492), National High Technology Research and Development Program of China (863 Program) (grant number 2006AAI0ZIE3).

\section{References}

I. Eskenazi B, Warner ML: Epidemiology of endometriosis. Obstet Gynecol Clin North Am 1997, 24(2):235-258.

2. Giudice LC, Kao LC: Endometriosis. Lancet 2004, 364(9447): I789- 1799.

3. Bulun SE: Endometriosis. N Engl / Med 2009, 360(3):268-279.

4. Sha G, Wu D, Zhang L, Chen X, Lei M, Sun H, Lin S, Lang J: Differentially expressed genes in human endometrial endothelial cells derived from eutopic endometrium of patients with endometriosis compared with those from patients without endometriosis. Hum Reprod 2007, 22(12):3159-3169.

5. Kato N, Sasou S, Motoyama T: Expression of hepatocyte nuclear factor-I beta (HNF-I beta) in clear cell tumors and endometriosis of the ovary. Mod Pathol 2006, I 9(I):83-89.
6. Eyster KM, Boles AL, Brannian JD, Hansen KA: DNA microarray analysis of gene expression markers of endometriosis. Fertil Steril 2002, 77(I):38-42.

7. Lebovic DI, Baldocchi RA, Mueller MD, Taylor RN: Altered expression of a cell-cycle suppressor gene, Tob- $I$, in endometriotic cells by cDNA array analyses. Fertil Steril 2002, 78(4):849-854.

8. Arimoto $T$, Katagiri $T$, Oda $K$, Tsunoda $T$, Yasugi $T$, Osuga $Y$, Yoshikawa H, Nishii O, Yano T, Taketani Y, Nakamura Y: Genomewide cDNA microarray analysis of gene-expression profiles involved in ovarian endometriosis. Int J Oncol 2003, 22(3):55I-560.

9. Kao LC, Germeyer A, Tulac S, Lobo S, Yang JP, Taylor RN, Osteen K, Lessey BA, Giudice LC: Expression profiling of endometrium from women with endometriosis reveals candidate genes for disease-based implantation failure and infertility. Endocrinology 2003, 144(7):2870-288I.

10. Fan Y, Chen BL, Ma XD, Su MQ: Detection of expression of endometriosis-related cytokine and their receptor genes by cDNA microarray technique. Xi Bao Yu Fen Zi Mian Yi Xue Za Zhi 2005, 2 I (4):489-492.

II. Matsuzaki S, Canis M, Pouly JL, Dechelotte P, Okamura K, Mage G: The macrophage stimulating protein/RON system: a potential novel target for prevention and treatment of endometriosis. Mol Hum Reprod 2005, I I (5):345-349.

12. Matsuzaki S, Canis M, Vaurs-Barriere C, Boespflug-Tanguy O, Dastugue B, Mage G: DNA microarray analysis of gene expression in eutopic endometrium from patients with deep endometriosis using laser capture microdissection. Fertil Steril 2005, 84(Suppl 2): I I80- I 190.

13. Wu Y, Kajdacsy-Balla A, Strawn E, Basir Z, Halverson G, Jailwala P, Wang Y, Wang X, Ghosh S, Guo SW: Transcriptional characterizations of differences between eutopic and ectopic endometrium. Endocrinology 2006, I47(I):232-246.

14. Burney R, Talbi S, Hamilton A, Vo K, Nyegaard M, Nezhat C, Lessey B, Giudice L: Gene Expression Analysis of Endometrium Reveals Progesterone Resistance and Candidate Susceptibility Genes in Women with Endometriosis. Endocrinology 2007, I48(8):38I4.

15. Eyster KM, Klinkova O, Kennedy V, Hansen KA: Whole genome deoxyribonucleic acid microarray analysis of gene expression in ectopic versus eutopic endometrium. Fertil Steril 2007, 88(6): | $505-1533$.

16. Hever A, Roth R, Hevezi P, Marin M, Acosta J, Acosta H, Rojas J, Herrera $R$, Grigoriadis $D$, White $E$ : Human endometriosis is associated with plasma cells and overexpression of B lymphocyte stimulator. Proceedings of the National Academy of Sciences 2007, 104(30): $1245 \mid$.

17. Hull ML, Escareno CR, Godsland JM, Doig JR, Johnson CM, Phillips SC Smith SK, Tavare S, Print CG, Charnock-Jones DS: Endometrialperitoneal interactions during endometriotic lesion establishment. Am / Pathol 2008, 173(3):700-7I5.

18. Subramanian A, Tamayo P, Mootha VK, Mukherjee S, Ebert BL, Gillette MA, Paulovich A, Pomeroy SL, Golub TR, Lander ES, Mesirov JP: Gene set enrichment analysis: a knowledge-based approach for interpreting genome-wide expression profiles. Proc Natl Acad Sci USA 2005, 102(43): $15545-15550$.

19. Mootha VK, Lindgren CM, Eriksson KF, Subramanian A, Sihag S, Lehar J, Puigserver P, Carlsson E, Ridderstrale M, Laurila E, Houstis N, Daly MJ, Patterson N, Mesirov JP, Golub TR, Tamayo P, Spiegelman B, Lander ES, Hirschhorn JN, Altshuler D, Groop LC: PGC-I alpharesponsive genes involved in oxidative phosphorylation are coordinately downregulated in human diabetes. Nat Genet 2003, 34(3):267-273.

20. Jing Shi, Walker MG: Gene set enrichment analysis (GSEA) for interpreting gene expression profiles. Current Bioinformatics 2007, 2(2): 133-137.

2I. Gentleman RC, Carey VJ, Bates DM, Bolstad B, Dettling M, Dudoit S, Ellis B, Gautier L, Ge Y, Gentry J, Hornik K, Hothorn T, Huber W, lacus S, Irizarry R, Leisch F, Li C, Maechler M, Rossini AJ, Sawitzki G, Smith C, Smyth G, Tierney L, Yang JY, Zhang J: Bioconductor: open software development for computational biology and bioinformatics. Genome Biol 2004, 5( I 0):R80.

22. R Development Core Team: R: A language and environment for statistical computing. 2009 [http://www.R-project.org/]. R Foundation for Statistical Computing, Vienna, Austria ISBN 3-90005 I-07-0 
23. Irizarry RA, Hobbs B, Collin F, Beazer-Barclay YD, Antonellis KJ, Scherf U, Speed TP: Exploration, normalization, and summaries of high density oligonucleotide array probe level data. Biostatistics 2003, 4(2):249-264.

24. Gautier L, Cope L, Bolstad BM, Irizarry RA: affy--analysis of Affymetrix GeneChip data at the probe level. Bioinformatics 2004, 20(3):307-315.

25. Using Categories to Model Genomic Data 2009 [http:// www.bioconductor.org/packages/2.4/bioc/vignettes/Category/inst/ doc/Category.pdf]

26. Manoli T, Gretz N, Grone H-J, Kenzelmann M, Eils R, Brors B: Group testing for pathway analysis improves comparability of different microarray datasets. Bioinformatics 2006, 22(20):2500-2506.

27. Sinaii N, Cleary SD, Ballweg ML, Nieman LK, Stratton P: High rates of autoimmune and endocrine disorders, fibromyalgia, chronic fatigue syndrome and atopic diseases among women with endometriosis: a survey analysis. Hum Reprod 2002, I 7(1 0):27| 5-2724.

28. Lebovic DI, Mueller MD, Taylor RN: Immunobiology of endometriosis. Fertility and Sterility 200I, 75(I): I-I0.

29. Berbic M, Schulke L, Markham R, Tokushige N, Russell P, Fraser IS: Macrophage expression in endometrium of women with and without endometriosis. Hum Reprod 2009, 24(2):325-332.

30. Ferrero S, Petrera P, Colombo BM, Navaratnarajah R, Parisi M, Anserini $\mathrm{P}$, Remorgida $\mathrm{V}$, Ragni $\mathrm{N}$ : Asthma in women with endometriosis. Hum Reprod 2005, 20( I 2):35 I4-35I7.

31. Matorras R, Ocerin I, Unamuno M, Nieto A, Peiro E, Burgos J, Exposito A: Prevalence of endometriosis in women with systemic lupus erythematosus and Sjogren's syndrome. Lupus 2007, I 6(9):736-740.

32. de Bakker PIW, McVean G, Sabeti PC, Miretti MM, Green T, Marchini J, Ke XY, Monsuur AJ, Whittaker P, Delgado M, Morrison J, Richardson A, Walsh EC, Gao XJ, Galver L, Hart J, Hafler DA, Pericak-Vance M, Todd JA, Daly MJ, Trowsdale J, Wijmenga C, Vyse TJ, Beck S, Murray SS, Carrington M, Gregory S, Deloukas P, Rioux JD: A high-resolution HLA and SNP haplotype map for disease association studies in the extended human MHC. Nature Genet 2006, 38(10): I |66-I |72.

33. Starzinski-Powitz A, Handrow-Metzmacher H, Kotzian S: The putative role of cell adhesion molecules in endometriosis: can we learn from tumour metastasis? Molecular Medicine Today 1999, 5(7):304-309.

34. Wu MY, Ho HN, Chen SU, Chao KH, Chen CD, Yang YS: Increase in the production of interleukin-6, interleukin-10, and interleukin-I 2 by lipopolysaccharide-stimulated peritoneal macrophages from women with endometriosis. Am J Reprod Immunol 1999, 4I(I): I06-III.

35. Ho HN, Wu MY, Chao KH, Chen CD, Chen SU, Yang YS: Peritoneal interleukin-IO increases with decrease in activated CD4+ T lymphocytes in women with endometriosis. Hum Reprod I997, I 2(I I):2528-2533.

36. Ho HN, Wu MY, Chao KH, Chen CD, Chen SU, Chen HF, Yang YS: Decrease in interferon gamma production and impairment of T-lymphocyte proliferation in peritoneal fluid of women with endometriosis. Am / Obstet Gynecol 1996, I 75(5):1236-124I.

37. Keenan JA, Chen TT, Chadwell NL, Torry DS, Caudle MR: IL-I beta, TNF-alpha, and IL-2 in peritoneal fluid and macrophage-conditioned media of women with endometriosis. Am J Reprod Immunol 1995, 34(6):381-385

38. Harada T, Yoshioka H, Yoshida S, Iwabe T, Onohara Y, Tanikawa M, Terakawa N: Increased interleukin-6 levels in peritoneal fluid of infertile patients with active endometriosis. Am J Obstet Gynecol 1997, I 76(3):593-597.

39. Punnonen J, Teisala K, Ranta H, Bennett B, Punnonen R: Increased levels of interleukin- 6 and interleukin- 10 in the peritoneal fluid of patients with endometriosis. Am J Obstet Gynecol 1996, I 74(5): I 522-I 526.

40. Hornung D, Bentzien F, Wallwiener D, Kiesel L, Taylor RN: Chemokine bioactivity of RANTES in endometriotic and normal endometrial stromal cells and peritoneal fluid. Mol Hum Reprod 2001, 7(2): |63-168.

4I. Ponce C, Torres M, Galleguillos C, Sovino H, Boric MA, Fuentes A, Johnson MC: Nuclear Factor kappa B (NF\{kappa\}B) pathway and Interleukin-6 (IL-6) are affected in eutopic endometrium of women with endometriosis. Reproduction 2009.
42. Seto-Young D, Avtanski D, Strizhevsky M, Parikh G, Patel P, Kaplun J, Holcomb K, Rosenwaks Z, Poretsky L: Interactions among Peroxisome Proliferator Activated Receptor-\{gamma\}, Insulin Signaling Pathways, and Steroidogenic Acute Regulatory Protein in Human Ovarian Cells. J Clin Endocrinol Metab 2007, 92(6):2232-2239.

43. Bulun SE, Yang S, Fang Z, Gurates B, Tamura M, Sebastian S: Estrogen production and metabolism in endometriosis. Ann NY Acad Sci 2002, 955:75-85.

44. Tamaya T, Motoyama T, Ohono $\mathrm{Y}$, Ide N, Tsurusaki T, Okada H: Steroid receptor levels and histology of endometriosis and adenomyosis. Fertil Steril 1979, 3 I(4):396-400.

45. Janne O, Kauppila A, Kokko E, Lantto T, Ronnberg L, Vihko R: Estrogen and progestin receptors in endometriosis lesions: comparison with endometrial tissue. Am J Obstet Gynecol 198I, | 4 | (5):562-566.

46. Lyndrup J, Thorpe S, Glenthoj A, Obel E, Sele V: Altered progesterone/estrogen receptor ratios in endometriosis. A comparative study of steroid receptors and morphology in endometriosis and endometrium. Acta Obstet Gynecol Scand 1987, 66(7):625-629.

47. Bergqvist $A$, Ferno M: Estrogen and progesterone receptors in endometriotic tissue and endometrium: comparison according to localization and recurrence. Fertil Steril 1993, 60(I):63-68.

48. Yamashita $Y$, Asano M, Morishima S, Fujino K, Terai Y, Ohmichi M: Mitochondrial gene expression in granulosa cells of severe endometriosis with in vitro fertilization and embryo transfer. Fertil Steril 2007, 88(6): | 703-1705.

49. Kao LC, Germeyer A, Tulac S, Lobo S, Yang JP, Taylor RN, Osteen K, Lessey BA, Giudice LC: Expression Profiling of Endometrium from Women with Endometriosis Reveals Candidate Genes for Disease-Based Implantation Failure and Infertility. Endocrinology 2003, I44(7):2870-288I.

50. Sherwin JRA, Sharkey AM, Mihalyi A, Simsa P, Catalano RD, D'Hooghe TM: Global gene analysis of late secretory phase, eutopic endometrium does not provide the basis for a minimally invasive test of endometriosis. Hum Reprod 2008, 23(5): $1063-1068$

Publish with Bio Med Central and every scientist can read your work free of charge

"BioMed Central will be the most significant development for disseminating the results of biomedical research in our lifetime. "

Sir Paul Nurse, Cancer Research UK

Your research papers will be:

- available free of charge to the entire biomedical community

- peer reviewed and published immediately upon acceptance

- cited in PubMed and archived on PubMed Central

- yours - you keep the copyright
BioMedcentral 